\title{
First effects of a multicomponent treatment for sleep disorders in children
}

This article was published in the following Dove Press journal:

Nature and Science of Sleep

2I December 2010

Number of times this article has been viewed

\author{
Angelika A Schlarb' \\ Kerstin Velten-Schurian' \\ Christian F Poets ${ }^{2}$ \\ Martin Hautzinger ${ }^{1}$ \\ 'Faculty of Science, Department \\ of Psychology, ${ }^{2}$ Department \\ of Neonatology, University Hospital \\ Tübingen, University of Tübingen, \\ Tübingen, Germany
}

\begin{abstract}
Insomnia in children is a common disorder, yet only few child-specific treatment modalities exist so far. The goal of this study was to investigate the effectiveness of a multicomponent intervention program for children with insomnia at 5-10 years of age and their parents. The program was a structured six-session behavioral and hypnotherapeutic group treatment with three sessions for the children and three for their parents. Thirty-eight children (5.1-10.9 years) were randomly assigned to the specific treatment condition or waiting list plus sleep diary control condition. Twenty-two children participated in the treatment group and 16 in the control group. All children suffered from insomnia according to the International Classification of Sleep Disorders criteria. Sleep symptoms were assessed with a sleep diary and the German version of the Children Sleep Habit Questionnaire (CSHQ) and the Sleep Disturbance Scale for Children (SDSC). Although both conditions showed a significant decrease in several sleep symptoms, the treatment group exhibited a significantly greater improvement with regard to CSHQ and SDSC total scores as well as in several sleep parameters, reflecting the most important features of the intervention program, such as bedtime, sleep-related anxiety, night waking, and sleeping in parents' bed. By contrast, the control group's data revealed only unspecific effects. These pilot data suggest that insomnia in childhood can be treated effectively with this child-specific multicomponent group treatment.
\end{abstract}

Keywords: sleep disorders in children, behavioral insomnia, behavioral therapy, hypnotherapy, group therapy, imagery

\section{Introduction}

The present study investigates the effectiveness of a multicomponent group treatment program for children with sleep disorders. So far, only few child-specific sleep treatment modalities exist, and research has primarily focused on interventions for very young children. This program was specifically designed for children at the age of 5-10 years.

The relevance of sleep problems in children and thus the importance of treatment are being increasingly recognized. Prevalence estimates in school children vary between $20 \%{ }^{1}$ and $43 \% .{ }^{2}$ Children with sleep disorders often show behavior incompatible with healthy sleep, such as playing, reading, eating, or watching TV in bed. ${ }^{3}$ Furthermore, psychological factors, such as anxiety, depression, or defiance problems have an impact on the child's sleep and his or her daily behavior. ${ }^{4-6}$ Finally, poor parenting strategies, marital conflicts, and environmental factors, such as light, noise, or parents' smoking can lead to sleep difficulties. ${ }^{7-10}$

Several impairments due to diminished sleep quantity and quality are related to cognitive functioning and working memory ${ }^{11-17}$ as well as to lower school performance. ${ }^{18,19}$ Faculty of Science, Department of Psychology, University of Tübingen, Christophstr. 2, 72072 Tübingen, Germany Tel +4970712977185

Fax +49 707I 295219

Email angelika.schlarb@uni-tuebingen.de 
It is important to bear in mind that early sleep problems tend to persist in nearly two-thirds of children. ${ }^{20-22}$ This is very problematic because persisting sleep disturbances are correlated with internalizing and externalizing behavioral disorders $^{23-29}$ or can lead to a psychiatric disorder 5 years later, ${ }^{30}$ such as depression/anxiety, inattention/hyperactivity, and aggression. ${ }^{31}$ Finally, sleep disorders in children are associated with parental distress. ${ }^{32,33}$

Most existing intervention strategies focus on toddlers or young children at the age of up to 5 years. ${ }^{34-45}$ Others focus on children with special needs ${ }^{46,47}$ or on specific topics, such as nighttime fears. ${ }^{48-51}$ Intervention programs for young children encourage the child to fall asleep in his or her own bed and to return to sleep after waking up at night. ${ }^{40,52-54}$ To our knowledge, there has been no multicomponent group treatment for children at the age of 5-10 years. For this reason, the goal of the present study was to develop a treatment program for children in this age group to deal with difficulty in sleeping by themselves and to enable the parents to establish positive education strategies to help their children overcome their sleep problems. A further goal was to evaluate the outcome of our intervention program in a controlled pilot trial.

\section{Materials and methods}

\section{KiSS: a multicomponent group treatment for children with insomnia}

We developed KiSS as a six-session multicomponent treatment with 4-6 children in each group. Each weekly session has a duration of about $100 \mathrm{~min}$. Three sessions are conducted for children and three for parents. Components are based on established strategies ${ }^{55-57}$ and include stimulus control (SC) instructions, sleep hygiene education, and cognitive therapy for children and parents as well as imaginative or hypnotherapeutic and relaxation techniques for children. The children receive a soft toy, the leopard Kalimba, which is employed as a coping model and therapy puppet. Each session starts with a review of homework and sleep behavior instructions and ends with hypnotherapeutic imagination exercises. Subsequently, the implemented therapeutic strategies will be described.

\section{SC}

$\mathrm{SC}$ is one of the most effective single-component therapies for insomnia in adults ${ }^{55,58,59}$ and has been shown to be effective in multicomponent interventions. ${ }^{55,58,60} \mathrm{SC}$ is based on a functional analysis in which falling asleep by oneself is coupled with reinforcement. Thus, stimuli associated with sleep become discriminative stimuli for the occurrence of reinforcement. For some children, bedtime is the first quiet time during the day. They are unable to relax and self-sooth.
Under these conditions, bed and bedtime become cues for arousal rather than sleep. ${ }^{61}$ In addition, internal cues, such as physiological arousal, anticipatory anxiety because of monsters or burglars can become interoceptive cues for further arousal and sleep disruption.

SC instructions are implemented in the KiSS sleep treatment to increase the frequency of quickly falling asleep and maintaining sleep throughout the night by enhancing the cues for sleep and at the same time decreasing the cues for sleepincompatible behavior. The respective treatment components consist of a set of instructions for the parents and for the child to help them 1) establish a consistent sleep-wake rhythm, 2) modify the bed and the bedroom in order to enhance them as cues for sleep (eg, painting the wall in blue, having nice and calming drawings, and new bed linen), 3) weaken them as cues for activities that might be incompatible or interfere with sleep (eg, no TV, computer games, or cell phone etc), and 4) establish sleep-related rituals and routines that are stimulus-oriented and based on the child's needs (eg, bedtime stories, brushing the teeth, and dimming the light).

\section{Sleep hygiene education}

Sleep hygiene education includes basic information about sleep and is a core component of cognitive-behavioral treatment of insomnia. ${ }^{62}$ Inadequate sleep hygiene, such as irregular sleep-wake schedules, is common in families with children suffering from a sleep disorder. According to Manber et $\mathrm{al}^{56}$ regularizing sleep-wake schedules is a powerful means of decreasing daytime sleepiness in children and young adults. During the KiSS treatment program, parents receive sleep hygiene instructions depending on the children's age, such as avoiding extended time in bed, irregular sleep-wake schedules, or agitating games close to bedtime.

\section{Cognitive strategies}

Insomniacs often have a number of irrational beliefs about sleep. In children aged 5-10 years, these beliefs often relate to a lack of self-efficacy to cope with their sleep problems. At that age, caregivers are the ones who are able to help. However, caregivers often suffer themselves from maladaptive sleep-related cognitions with regard to their child. Different types of dysfunctional cognitions in caregivers or their children have been identified. ${ }^{55} 1$ ) misconceptions about the causes of insomnia (in particular, parents think that the cause is physical discomfort), 2) misattributions of the consequences of poor sleep (eg, 'poor sleep leads directly to psychological and intellectual discomfort'), 3) unrealistic sleep expectations (eg, 'my child has to sleep without any interruption'), 4) diminished perceptions of control and 
predictability of sleep (eg, 'I have no influence on my child's sleep'), and 5) false beliefs about sleep-promotion practices (eg, drinking at night, giving a bottle in the evening until the child falls asleep). In the KiSS treatment program, the cognitive interventions are directed to change maladaptive attitudes and restructure dysfunctional beliefs of both parents and children.

\section{Hypnotherapeutic strategies}

Numerous studies have shown that hypnotic susceptibility is related to the capacity of imaginative involvement and that children generally enter the hypnotic state more easily than adults. ${ }^{63,64}$ Norms of hypnotizability have been defined and it has been found that the peak of susceptibility is in childhood at the age of 7-14 years. ${ }^{65}$ Hypnotherapy has been applied in a diversity of childhood problems ${ }^{66-68}$ With regard to sleep disorders, there have been mostly single case studies or small treatment groups (TGs) and no control group (CG) studies. ${ }^{69-71}$ Only Anbar and Slothower ${ }^{57}$ applied hypnosis in a large sample of 84 children with insomnia at the age of 7-17 years and found a significant decrease in symptoms. However, they did not use a CG design.

In the KiSS treatment program, hypnotherapeutic tools are implemented in order to enhance personal control as well as to create awareness of physical changes that occur in relation to changes in the mind. ${ }^{72}$ All children receive a soft toy, the leopard Kalimba, which is a coping model and therapy puppet. Kalimba as a leopard is associated with courage, selfconfidence, and strength, and serves as a coping model because when he was younger he used to have sleep problems too. Furthermore, his spots function as memory keepers for the techniques the children learn in the sleep treatment.

\section{Relaxation techniques}

Relaxation techniques in children are effective in the treatment of various disorders. ${ }^{73}$ One possibility to induce relaxation is diaphragmatic breathing. The goal is to enable children to relax quickly in every situation, in particular when lying down or when faced with stressful situations, such as waking up at night. For this reason, we developed the Kalimba magic-breathing technique. The children learn 'belly breathing' to release mental and physical stress and to induce a state of relaxation.

\section{Design}

A waiting list $C G$ design was employed to illustrate changes in different sleep indices over a time period of 3 weeks. Participants were randomly distributed to either the TG or the waiting list CG. The CG kept a sleep diary and had the possibility to participate in the treatment program after the waiting period. In addition to group, time was included as an independent variable in all analyses. All sleep data were assessed before the treatment $(\mathrm{tl})$ and 1 week after the treatment or waiting period (t2) (Table 1).

\section{Participants}

In total, 38 children ( 20 girls, 18 boys) and their parents participated in the study. All children met the criteria of insomnia according to the diagnostic guidelines of the International Classification of Sleep Disorders (ICSD-II). ${ }^{74}$ Their mean age was 7.8 years (range: $5.1-10.3$ ). Overall, 12 of the 38 children went to kindergarten and 26 to primary school. Except for two children who lived with single mothers, all children lived with both biological parents. Most of the children (65.8\%) had one sibling.

The mean age of the mothers was 38.6 years (range: $30-48$ years; $\mathrm{SD}=4.52$ ) and of the fathers 41.6 years (range: $30-55$ years; $\mathrm{SD}=6.19)$. The majority of the parents had a high educational level, ie, $76.3 \%$ had a higher education entrance qualification. Two mothers were single parents, one living with a new partner. Most mothers had a job (63.2\%), whereas $31.6 \%$ stayed at home and $2.6 \%$ were unemployed. Eighty-nine percent of the fathers had a job. All families had sufficient German language skills and signed the informed consent form. Except for one mother who was Asian, all participants were Caucasian. A total of 22 were in the TG and 16 in the waiting list (CG).

\section{TG}

Of the 22 children in the TG, 8 went to kindergarten, and 14 to primary school. Their mean age was 7.9 years (range: 5.1-10.3).

\section{Waiting list CG}

Four of the children participating in the waiting list $C G$ went to kindergarten, whereas 12 were in primary school. Their mean age was 7.7 years (range: $5.2-10.2$ ).

\section{Preanalysis}

The CG did not differ in any parameter from the experimental group (demographic variables, sleep disorders, sleep scores, etc). The $t$-tests with correction for multiple testing did not reveal any significant differences in any of the relevant variables (all $P>0.05$ ).

\section{Procedure}

All subjects were recruited through pediatricians, the local university children's hospital, and several kindergartens. 
Table I The KiSS treatment: contents of the sessions for children and their parents

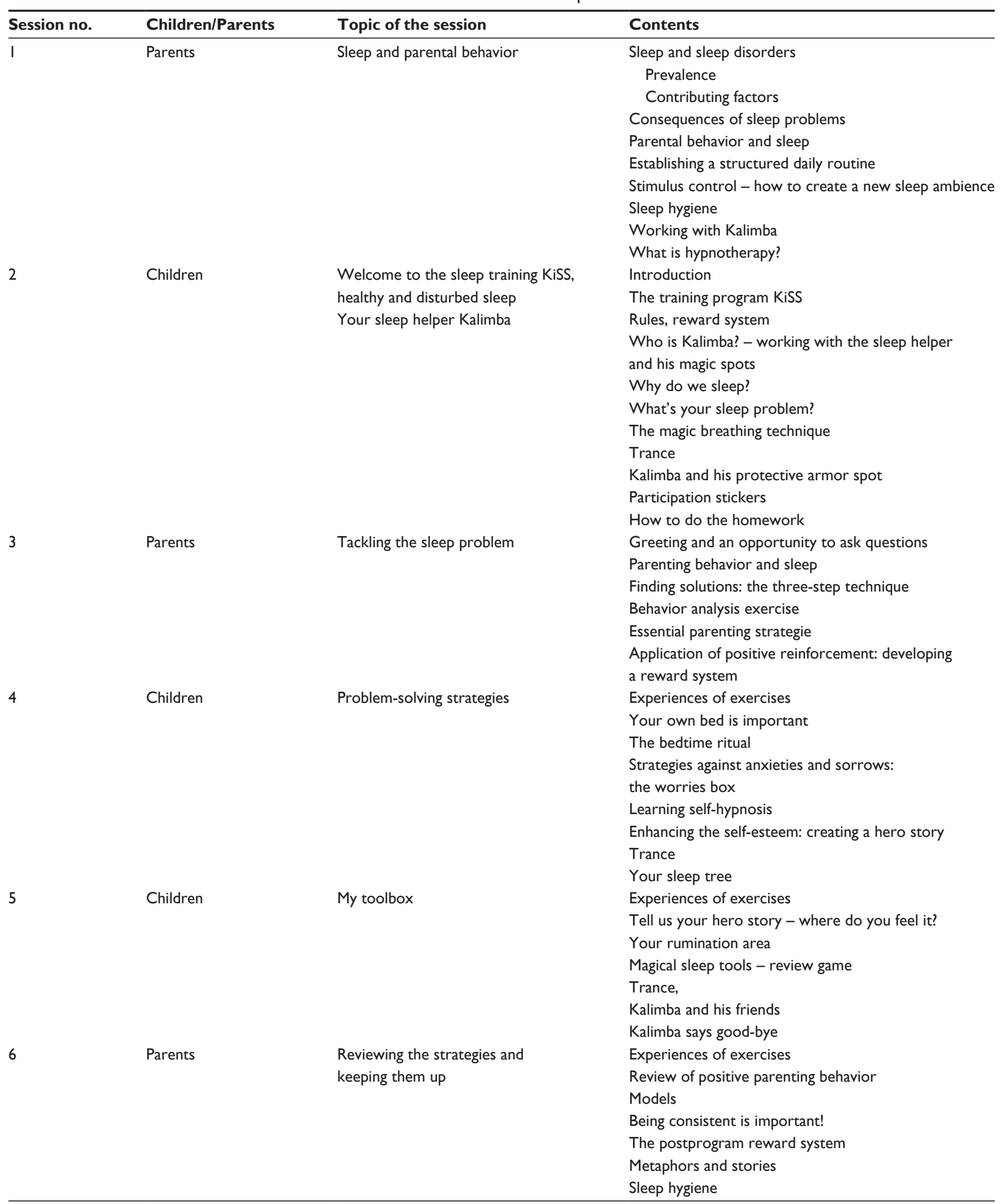

They were admitted to the study as soon as they had completed the baseline questionnaire, and written consent had been obtained from at least one parent and the child (if the child was at least 8 years old). At the screening appointment, the sleep diary containing sleep data from the previous 2 weeks was collected. A structured interview with the parents was employed to identify the child's sleep problems according to the ICSD-II. ${ }^{74}$ To screen for potential comorbid mental 
disorders (according to Diagnostic and Statistical Manual of Mental Disorders, 4th Edition), a second structured interview was carried out. All interviews were conducted by an independent clinician. After this comprehensive diagnostic procedure, families were randomly assigned to one of two conditions: 1) behavioral and hypnotherapeutic TG or 2) sleep diary waiting list CG. Parents and children of both conditions were instructed to fill out the sleep diaries on a daily basis ( 2 weeks before treatment, during the 3 weeks of treatment or waiting condition and 1 week after the intervention program). In addition, the parents answered questionnaires (Children Sleep Habit Questionnaire [CSHQ] and Sleep Disturbance Scale for Children [SDSC]) before treatment (premeasurement, tl) and 1 week after the treatment (postmeasurement, t2). After the TG was finished, the waiting list group took part in the intervention program. The study protocol was approved by the university ethics committee.

\section{Diagnosis}

In total, 29 children suffered from behavioral insomnia, 15 of them meeting the criteria of a sleep-onset association disorder (SOAD) and 14 of a limit-setting sleep disorder (LSSD). Five of the children showed inadequate sleep hygiene, three children fulfilled the criteria of psychophysiological insomnia, and one had adjustment insomnia. As represented in Table 2 , nearly $80 \%$ of the children had an additional sleep disorder such as psychophysiological insomnia, inadequate sleep hygiene, or behavioral insomnia of childhood. Behavioral insomnia in childhood with the subtype SOAD was most frequently diagnosed followed by inadequate sleep hygiene or limit-setting sleep disorder. Furthermore, $24 \%$ of the children showed symptoms of separation anxiety and 5\% symptoms of attention-deficit hyperactivity disorder.

According to the parents' reports, $60.5 \%$ of the children had a history of sleep problems in infancy and $71.1 \%$ in early childhood.

Table 2 Sleep disorders

\begin{tabular}{|c|c|c|c|c|c|c|}
\hline \multirow{2}{*}{$\begin{array}{l}\text { Condition } \\
\text { Sleep disorder }\end{array}$} & \multicolumn{2}{|c|}{ All } & \multicolumn{2}{|c|}{ TG } & \multicolumn{2}{|c|}{ CG } \\
\hline & $\mathbf{N}$ & $\%$ & $\mathbf{N}$ & $\%$ & $\mathbf{N}$ & $\%$ \\
\hline Behavioral insomnia in childhood & 29 & 76 & 17 & 77.3 & 12 & 75 \\
\hline $\begin{array}{l}\text { Sleep-onset association disorder } \\
\text { (SOAD) }\end{array}$ & 15 & 39 & 9 & 46.9 & 6 & 37.5 \\
\hline $\begin{array}{l}\text { Limit-setting sleep disorder } \\
\text { (LSSD) }\end{array}$ & 14 & 37 & 9 & 46.9 & 5 & 31.3 \\
\hline Inadequate sleep hygiene & 5 & 13 & 3 & 13.6 & 2 & 12.5 \\
\hline Psychophysiological insomnia & 3 & 8 & 2 & 9.1 & 1 & 6.3 \\
\hline Adjustment insomnia & I & 3 & I & 4.6 & 0 & 0 \\
\hline Total & 38 & 100 & 22 & 100 & 16 & 100 \\
\hline Additional sleep disorder & 30 & 78.9 & 17 & 77.3 & 13 & 81.3 \\
\hline
\end{tabular}

\section{Instruments}

\section{Sleep history and sleep diagnosis}

Information about the child's sleep history was gained following Owen's BEAR method ${ }^{75}$ sleep screening tool (bedtime problems, excessive daytime sleepiness, awakenings during the night, regularity and duration of sleep, snoring).

The child's sleep disorder was assessed by means of a structured clinical interview with the parents based on the diagnostic criteria of the ICSD-II. ${ }^{74}$ The interview surveys the following sleep disorders: 1) adjustment insomnia, 2) psychophysiological insomnia, 3) insomnia due to mental disorder, 4) inadequate sleep hygiene, and 5) behavioral insomnia of childhood; furthermore, screening questions with regard to 6) narcolepsy, 7) sleep-related breathing disorders, and 8) parasomnias are included.

\section{Exclusion of another mental disorder}

To rule out the presence of another mental disorder which might be causing the sleep disorder, we conducted the Anxiety Disorders Interview Schedule-Revised ${ }^{76}$ in a German version for children and adolescents. ${ }^{77}$

\section{Feedback questionnaire for parents}

An anonymous feedback questionnaire was constructed to evaluate the acceptance and the content of the treatment. The questionnaire consisted of 10 questions about the treatment. Furthermore, parents were asked to answer two open questions: 'Which parts of the training were most helpful?' and 'What would you like to see improved?'

\section{Sleep measures}

\section{Sleep diary}

The sleep diary was used as a common instalment for measuring sleep difficulties. Minde et $\mathrm{al}^{78}$ refer to a Cronbach's alpha of 0.77 for internal consistency. Parents were asked to fill out a 2-week sleep diary about their child's bedtime, rising time, duration of bedtime procedure, sleep onset latency, frequency and duration of night waking, and as a main topic the frequency of the child sleeping in the parental bed.

\section{SDSC}

The $\mathrm{SDSC}^{79}$ is a parent-report instrument for evaluating sleep disturbances in school-aged children. The tool is a 26-item Likert-type rating scale with six subscales (Sleep-Wake Transition Disorders, Disorders of Initiating and Maintaining Sleep [DIMS], Disorders of Arousal/Nightmares [DA], Sleep Hyperhidrosis [SHY], Disorders of Excessive Somnolence [DOES], and Sleep Breathing Disorders [SBD]) with a cutoff 
score of 39. According to Bruni et $\mathrm{al}^{79}$ internal consistency was high in controls $(0.79)$ and at a satisfactory level in clinical subjects (0.71). The test/retest reliability was adequate for the total score (0.71) and the single-item scores.

\section{CSHQ}

To evaluate more behavioral aspects of the sleep problems, we also used the $\mathrm{CSHQ}^{80}$ which is a parent-report sleep screening instrument to identify both behaviorally and medically based sleep problems in school-aged children. The questionnaire yields a total score and eight subscale scores reflecting the key sleep domains that encompass the major medical and behavioral sleep disorders in this age group (Sleep Anxiety, Bedtime Resistance, Night Waking, Sleep Duration, Sleep Onset Delay, Daytime Sleepiness, Sleep-Disordered Breathing, Parasomnias) with a cutoff score of 41 . Owens et al ${ }^{80}$ report adequate internal consistency for both a community sample $(P=0.68)$ and a clinical sample $(P=0.78)$ and an acceptable test/retest reliability (range: $0.62-0.79$ ).

\section{Statistical analyses}

All computations were implemented with Statistical Package for Social Sciences (version 16; SPSS Inc, Chicago, IL). Differences between conditions regarding the children's age and gender as well as the parents' age and education level were tested by two-tailed $t$-tests and Mann-Whitney $U$ tests. For all dependent outcome measures, two-way repeated-measures ANOVAs (analysis of variance) were conducted with the two-level factor time (pre, post) and the two-level factor group (TG, waiting list sleep diary group). Furthermore, interaction effects for the CSHQ and the SDSC were calculated. We conducted a two-way repeated-measures ANOVA with the factors group and time as independent variables and the subscales of the SDSC as dependent variables. Statistical significance was set at $P<0.05$ for all statistical tests. Pearson's correlation coefficient $r$ was computed to determine effect sizes.

\section{Results Acceptance}

Program attendance rates were high. Families in the treatment condition attended on average 5.76 sessions $(\mathrm{SD}=0.66$; $88.2 \%$ attended all 6 sessions). No family dropped out of the treatment program. To evaluate the acceptance of the psychological treatment, the questionnaire was filled out after every session by the parents. They rated all feedback questions above the mean of 4.00 ( $1=$ not at all, $5=$ extremely). Nearly all parents indicated that the explained know-how was generally understandable $(M=4.69, \mathrm{SD}=0.50)$. They also rated their motivation to continue the sleep training as high $(M=4.69, \mathrm{SD}=0.55)$. The topics were of interest to them $(M=4.64, \mathrm{SD}=0.53)$, and they felt comfortable with the group throughout the treatment $(M=4.64, \mathrm{SD}=0.49)$. Tables 3 and 4 show the results in detail.

Most parents (61) rated the information about sleep and sleep disturbances as well as the sleep hygiene rules and trainers' advice as most helpful. In second place were the discussions which many parents (40) reported to be very helpful. The last question was about what parents wanted to change. Six parents requested more sessions, and three wanted quieter rooms.

\section{Sleep variables}

Sleep diary data

For this pilot study, the sleep diary data were assessed with regard to the child's sleeping in the parents' bed as this is a typical symptom of behavioral insomnia. At postmeasurement ( $\mathrm{t} 2$ ), the sleep diary data revealed a significant decrease in the frequency of sleeping in the parents' bed for both conditions $(\mathrm{F}(1,37)=15.56, P \leq 0.001, r=0.60)$. However, the children in the TG slept significantly more often in their own bed compared with the children in the waiting list (CG) $(\mathrm{F}(1,37)=6.20, P=0.019, r=0.43)$.

\section{SDSC}

As displayed in Table 5, at postmeasurement (t2), the children of both conditions showed significant improvements in the

Table 3 Feedback from parents about the contents of the KiSS treatment

\begin{tabular}{|c|c|c|c|c|}
\hline No. & Questions & Min & Max & $\begin{array}{l}\text { Mean } \\
\text { (SD) }\end{array}$ \\
\hline $\mathrm{I}$ & Today's topic was of interest to me. & 3 & 5 & $4.64(0.53)$ \\
\hline 2 & $\begin{array}{l}\text { The explained know-how was } \\
\text { generally understandable. }\end{array}$ & 3 & 5 & $4.69(0.50)$ \\
\hline 3 & $\begin{array}{l}\text { My individual situation was } \\
\text { addressed adequately. }\end{array}$ & 3 & 5 & $4.58(0.58)$ \\
\hline 4 & I received answers to my questions. & 2 & 5 & $4.62(0.61)$ \\
\hline 5 & $\begin{array}{l}\text { I am motivated to try new things } \\
\text { in my everyday life. }\end{array}$ & 2 & 5 & $4.60(0.60)$ \\
\hline 6 & $\begin{array}{l}\text { The offer for practice exercises } \\
\text { was adequate. }\end{array}$ & 1 & 5 & $4.16(0.82)$ \\
\hline 7 & $\begin{array}{l}\text { I received concrete support advice for } \\
\text { implementation in my everyday life. }\end{array}$ & 2 & 5 & $4.4 I(0.62)$ \\
\hline 8 & I felt comfortable in today's group. & 3 & 5 & $4.64(0.49)$ \\
\hline 9 & $\begin{array}{l}\text { There were enough opportunities } \\
\text { to engage with the group. }\end{array}$ & 2 & 5 & $4.35(0.78)$ \\
\hline 10 & $\begin{array}{l}\text { Today's parent meeting motivated me } \\
\text { to continue working on my child's } \\
\text { sleep problems. }\end{array}$ & 3 & 5 & $4.69(0.55)$ \\
\hline
\end{tabular}

Notes: Coding: I, not at all; 2, hardly; 3, not sure; 4, quite a bit; 5, extremely. 
Table 4 Feedback from parents about the contents of the KiSS treatment

\section{What was most helpful?}

Advice and information about sleep

Exchange of experiences with others

Individuality

Structuredness

Fantastic manual

Comfortable atmosphere

Instances

What should we improve within the KiSS training?

The session was too short

Appointments at other times

To improve room conditions (for instance, temperature

and loudness)

The session was too long

Pauses

Smaller groups

SDSC subscales, Sleep-Wake Transition Disorders (SWTD), DIMS, DA, and SBD. Nevertheless, there was a significantly higher improvement in the children of the TG compared with the waiting list $\mathrm{CG}$. The TG showed a significantly greater decrease in the total score $(\mathrm{F}(1,37)=5.09, P=0.034, r=0.43)$ and in the subscales, SWTD $(\mathrm{F}(1,37)=6.79, P=0.016$, $r=0.48)$, DIMS $(\mathrm{F}(1,37)=4.59, P=0.043, r=0.41)$, and $\mathrm{DA}(\mathrm{F}(1,37)=7.87, P=0.010, r=0.50)$.

\section{CSHQ}

The main results of the CSHQ are reported in Table 6 . A two-way repeated-measures ANOVA was conducted with the factors group and time as independent variables and each subscale of the CSHQ as dependent variables. Both conditions showed significant advances at postmeasurement (t2) in nearly every subscale. Nevertheless, the children of the TG reached a significantly greater decrease in the subscales, Bedtime Resistance $(\mathrm{F}(1,37)=4.17, P=0.049, r=0.34)$ and Sleep Anxiety $(\mathrm{F}(1,37)=19.18, P=0.028, r=0.38)$ as well as in the total score $(\mathrm{F}(1,37)=49.40, P=0.045, r=0.35)$ compared with the waiting list CG.

\section{Discussion}

The most important goals of this study were to develop a treatment program for children aged 5-10 years suffering from insomnia. Due to the diversity of the symptoms ranging from sleep onset associations to limit-setting problems and night anxieties, a multicomponent training was developed. First results show that the acceptance of the training was high. More than $88 \%$ of the families attended all sessions and no family dropped out of the treatment program. All feedback questions were rated above the mean of $4.00(1=$ not at all, $5=$ extremely). Furthermore, nearly all parents indicated that the explained know-how was generally understandable $(M=4.69, \mathrm{SD}=0.50)$ and rated their motivation to continue the sleep training as high $(M=4.69, \mathrm{SD}=0.55)$. The parents $(\mathrm{N}=61)$ rated the information about sleep and sleep disturbances as well as the sleep hygiene rules and trainers' advice as most helpful and reported that the discussions were very useful $(N=40)$.

Although the treatment and control condition showed significant improvements in most sleep parameters after the treatment or waiting period, the total scores of the CSHQ and the SDSC were significantly more reduced in the TG than in the waiting list (CG). Furthermore, the CSHQ subscales reflecting the most important features of the treatment

Table 5 Sleep Disturbance Scale for Children subscales

\begin{tabular}{|c|c|c|c|c|c|c|}
\hline & \multicolumn{2}{|c|}{ Treatment group (TG) } & \multicolumn{2}{|c|}{$\begin{array}{l}\text { Waiting list and sleep } \\
\text { diary group (CG) }\end{array}$} & \multirow[t]{2}{*}{$\begin{array}{l}\text { Effect } \\
\text { of time }\end{array}$} & \multirow[t]{2}{*}{$\begin{array}{l}\text { Interaction } \\
\text { effect }\end{array}$} \\
\hline & tl & t2 & tl & t2 & & \\
\hline $\begin{array}{l}\text { Sleep-wake transition } \\
\text { disorders (SWTD) }\end{array}$ & $\begin{array}{l}11.84 \\
(3.39)\end{array}$ & $\begin{array}{l}8.30 \\
(2.11)\end{array}$ & $\begin{array}{l}10.20 \\
(2.76)\end{array}$ & $\begin{array}{l}9.07 \\
(3.06)\end{array}$ & 0.000 & 0.016 \\
\hline $\begin{array}{l}\text { Disorders of initiating } \\
\text { and maintaining sleep } \\
\text { (DIMS) }\end{array}$ & $\begin{array}{l}18.90 \\
(3.20)\end{array}$ & $\begin{array}{l}13.77 \\
(5.35)\end{array}$ & $\begin{array}{l}16.30 \\
(4.87)\end{array}$ & $\begin{array}{l}15.70 \\
(4.60)\end{array}$ & 0.012 & 0.043 \\
\hline $\begin{array}{l}\text { Disorders of } \\
\text { arousal/nightmares (DA) }\end{array}$ & $\begin{array}{l}5.50 \\
(2.55)\end{array}$ & $\begin{array}{l}3.70 \\
(0.95)\end{array}$ & $\begin{array}{l}3.63 \\
(1.04)\end{array}$ & $\begin{array}{l}3.40 \\
(0.74)\end{array}$ & 0.001 & 0.010 \\
\hline $\begin{array}{l}\text { Sleep hyperhidrosis } \\
\text { (SHY) }\end{array}$ & $\begin{array}{l}2.70 \\
(1.38)\end{array}$ & $\begin{array}{l}2.30 \\
(0.67)\end{array}$ & $\begin{array}{l}2.80 \\
(1.15)\end{array}$ & $\begin{array}{l}2.60 \\
(1.55)\end{array}$ & 0.292 & 0.723 \\
\hline $\begin{array}{l}\text { Disorders of excessive } \\
\text { somnolence (DOES) }\end{array}$ & $\begin{array}{l}8.90 \\
(1.67)\end{array}$ & $\begin{array}{l}8.20 \\
(4.89)\end{array}$ & $\begin{array}{l}7.67 \\
(2.35)\end{array}$ & $\begin{array}{l}7.27 \\
(2.28)\end{array}$ & 0.394 & 0.815 \\
\hline $\begin{array}{l}\text { Sleep-breathing disorders } \\
\text { (SBD) }\end{array}$ & $\begin{array}{l}3.80 \\
(0.92)\end{array}$ & $\begin{array}{l}3.10 \\
(0.32)\end{array}$ & $\begin{array}{l}4.40 \\
(2.13)\end{array}$ & $\begin{array}{l}3.67 \\
(I . I I)\end{array}$ & 0.015 & 0.952 \\
\hline Total score & $\begin{array}{l}51.65 \\
(7.50)\end{array}$ & $\begin{array}{l}39.37 \\
(11.56)\end{array}$ & $\begin{array}{l}45.00 \\
(6.61)\end{array}$ & $\begin{array}{l}41.70 \\
(6.53)\end{array}$ & 0.001 & 0.034 \\
\hline
\end{tabular}


Table 6 Children Sleep Habit Questionnaire: main results of the subscales

\begin{tabular}{|c|c|c|c|c|c|c|}
\hline & \multicolumn{2}{|c|}{ Treatment group (TG) } & \multicolumn{2}{|c|}{$\begin{array}{l}\text { Waiting list and sleep } \\
\text { diary group (CG) }\end{array}$} & \multirow[t]{3}{*}{$\begin{array}{l}\text { Effect } \\
\text { of time }\end{array}$} & \multirow[t]{3}{*}{$\begin{array}{l}\text { Interaction } \\
\text { effect }\end{array}$} \\
\hline & tl & t2 & tl & t2 & & \\
\hline & Mean (SD) & Mean (SD) & Mean (SD) & Mean (SD) & & \\
\hline \multirow[t]{2}{*}{ Bedtime resistance } & II.II & 8.37 & 11.53 & 10.93 & 0.003 & 0.049 \\
\hline & $(3.19)$ & $(2.4 I)$ & $(2.42)$ & $(2.86)$ & & \\
\hline \multirow[t]{2}{*}{ Night waking } & 5.47 & 4.47 & 5.27 & 5.00 & 0.024 & 0.180 \\
\hline & $(1.74)$ & $(1.47)$ & $(1.75)$ & $(\mathrm{I} .4 \mathrm{I})$ & & \\
\hline \multirow[t]{2}{*}{ Sleep duration } & 6.53 & 4.74 & 6.13 & 5.00 & 0.001 & 0.406 \\
\hline & (l.68) & $(1.85)$ & $(2.20)$ & $(1.85)$ & & \\
\hline \multirow[t]{2}{*}{ Sleep onset delay } & 2.05 & 1.58 & 2.33 & 2.07 & 0.007 & 0.426 \\
\hline & $(0.85)$ & $(0.77)$ & $(0.82)$ & $(0.88)$ & & \\
\hline \multirow[t]{2}{*}{ Daytime sleepiness } & 14.26 & 12.53 & 13.93 & 12.40 & 0.005 & 0.850 \\
\hline & $(3.14)$ & $(3.10)$ & $(3.55)$ & $(4.01)$ & & \\
\hline \multirow[t]{2}{*}{ Sleep anxiety } & 8.58 & 5.63 & 8.27 & 7.40 & 0.000 & 0.028 \\
\hline & $(1.95)$ & $(2.22)$ & $(2.34)$ & $(2.32)$ & & \\
\hline Sleep-disordered & 3.05 & 3.05 & 3.27 & 3.00 & 0.058 & 0.058 \\
\hline breathing & $(0.229)$ & $(0.229)$ & $(0.594)$ & $(0.00)$ & & \\
\hline \multirow[t]{2}{*}{ Parasomnias } & 8.47 & 7.95 & 8.27 & 7.93 & 0.029 & 0.612 \\
\hline & $(1.07)$ & $(I .31)$ & $(1.67)$ & $(1.63)$ & & \\
\hline \multirow[t]{2}{*}{ Total score } & 55.42 & 44.74 & 54.93 & 49.80 & 0.000 & 0.045 \\
\hline & $(4.98)$ & $(10.70)$ & $(5.76)$ & $(5.45)$ & & \\
\hline
\end{tabular}

Note: Bold text show significant results.

program, such as Sleeping in Parents' Bed and Bedtime Resistance, showed a significantly larger decrease compared with the CG than other subscales, such as Sleep-Disordered Breathing. The SDSC results revealed a similar pattern: the subscales related to the most dominant treatment components, ie, SWTD, DIMS, and DA, showed significantly larger improvements compared with the CG. However, the subscales reflecting sleep problems that had not been in the focus of the treatment, such as SHY, did not differ between the conditions. These data clearly show that the effects in the treatment condition are attributable to the specific components of the intervention program, whereas the effects found in the control condition are highly unspecific.

This is also supported by the sleep diary data with regard to the significantly reduced sleeping time in the parents' bed which was one of the main components of the treatment program. It can be assumed that the effect is valid, as this symptom is not as difficult to notice as night waking which could be underestimated by parents. ${ }^{81}$

Nevertheless, the reduced time in the parents' bed might not only be attributable to the treatment but could have also been influenced by the group setting. In addition to the feeling of competence promoted by the leopard to overcome the fear of sleeping alone, a social comparison effect due to the group setting may have helped the children to stay in bed. ${ }^{82}$ More specifically, reporting the achievement of an objective, such as sleeping alone, in front of a group might have a rewarding effect itself. For this reason, an effect of group setting might be added to treatment effects.

Nevertheless, the sleep diary group also showed significant improvements in several sleep-related parameters. Different factors might have contributed to these results. One possible factor might be the 'expectation of healing, ${ }^{83}$ ie, parents' awareness of entering the psychological treatment program after the waiting period and their anticipation of improvement may have caused the effect. Another factor could have been the process of completing the sleep diary itself which may have served as an instrument of reality testing. Parents were asked to complete the diary every morning and evening which could have influenced their perception of sleep problems and thus might have reduced incorrect beliefs. The findings of Hiscock and Wake ${ }^{45}$ lend support to these assumptions. They showed that the improvement of the CG without sleep diary or treatment offer was considerably smaller compared to the behavioral TG. Finally, the diagnostic procedure, in particular the interviews, involved personal contact with sleep specialists. This might have had an effect on the subjective strain felt by the parents and their children.

In general, the waiting list $\mathrm{CG}$ used in the present design does not permit any conclusions about the difference in effect of keeping a sleep diary and waiting for treatment. Furthermore, it is not clear whether the treatment-specific improvements might be attributable to the therapists' attention rather than to the specific sleep-oriented therapeutic 
strategies. Future research should therefore include an attention-placebo-control condition to rule out the possibility of attention effects. However, the strength of the present waiting list $\mathrm{CG}$ design is that it differentiates between nonspecific sleep diary and waiting effects on the one hand and specific treatment effects on the other.

\section{Conclusion and future perspectives}

This study showed that our multicomponent group intervention program led to a significant decrease in children's sleep problems. The TG showed treatment-specific effects and significantly larger improvements compared with the waiting list CG who completed a sleep diary and received a treatment offer which led only to unspecific effects. Implementing behavioral treatment for bedtime problems and night waking in older children (aged $>5$ years), this study addressed two requested research goals of the American Academy of Sleep Medicine. ${ }^{84}$ Future research should account for effects of group setting, comparing single and group treatment, and for attention effects by means of an attention-placebo-control condition. A further goal in sleep research should be the design of disorder-specific treatments.

\section{Acknowledgments}

The study was supported by the Research Fund of the Medical School of Tubingen University, Germany (AKF 186/110).

\section{Disclosure}

This was not an industry-supported study. The authors Schlarb, Velten-Schurian, Poets, and Hautzinger have no conflict of interest to declare in this work. The views expressed in this article are those of the authors and do not necessarily reflect those of the funding agency. The study was conducted at the University of Tübingen, Faculty of Science, Department of Psychology, Christophstr. 2, 72072 Tübingen, Germany.

\section{References}

1. Mindell JA, Owens JA, Carskadon MA. Developmental features of sleep. Child Adolesc Psychiatr Clin N Am. 1999;8(4):695-725.

2. Kahn A, van de Merckt C, Rebuffat E, et al. Sleep problems in healthy preadolescents. Pediatrics. 1989;84(3):542-546.

3. Szymczak JT, Jasinska M, Pawlak E, Zwierzykowska M. Annual and weekly changes in the sleep-wake rhythm of school children. Sleep. 1993;16(5):433-435.

4. Anders TF, Eiben LA. Pediatric sleep disorders: a review of the past 10 years. J Am Acad Child Adolesc Psychiatry. 1997;36(1):9-20.

5. Dahl RE, Lewin DS. Pathways to adolescent health sleep regulation and behavior. J Adolesc Health. 2002;31 Suppl 6:175-184.

6. Sadeh A, McGuire JP, Sachs H, et al. Sleep and psychological characteristics of children on a psychiatric inpatient unit. J Am Acad Child Adolesc Psychiatry. 1995;34(6):813-819.
7. Frölich J, Lehmkuhl G. Diagnostik und Differentialdiagnostik von Schlafstorungen im Kindesalter. Fortschr Neurol Psychiatr. 1998;66: 553-569.

8. Kraenz S, Fricke L, Wiater A, Mitschke A, Breuer U, Lehmkuhl G. Schlafprobleme bei Schulanfangern. Erste Ergebnisse der Studie "Gesunder Schlaf fur Kolner Kinder”. Kinder Jugendarzt. 2003;34:562-569.

9. Mindell JA, Owens JA. A Clinical Guide to Pediatric Sleep: Diagnosis and Management of Sleep Problems in Children and Adolescents. Philadelphia, PA: Lippincott Williams and Wilkins; 2003.

10. Stores G. Practitioner review: assessment and treatment of sleep disorders in children and adolescents. $J$ Child Psychol Psychiatry. 1996;37(8):907-925.

11. Sadeh A, Gruber R, Raviv A. Sleep, neurobehavioral functioning, and behavior problems in school-age children. Child Dev. 2002;73(2): 405-417.

12. Sadeh A, Gruber R, Raviv A. The effects of sleep restriction and extension on school-age children: what a difference an hour makes. Child Dev. 2003;74(2):444-455.

13. Epstein R, Chillag N, Lavie P. Starting times of school: effects on daytime functioning of fifth-grade children in Israel. Sleep. 1998;21(3): 250-256.

14. Wolfson AR, Carskadon MA. Sleep schedules and daytime functioning in adolescents. Child Dev. 1998;69(4):875-887.

15. Meijer AM, van den Wittenboer GLH. The joint contribution of sleep, intelligence and motivation to school performance. Pers Individ Dif. 2004;37(1):95-106.

16. Touchette E, Petit D, Seguin JR, Boivin M, Tremblay RE, Montplaisir JY. Associations between sleep duration patterns and behavioral/cognitive functioning at school entry. Sleep. 2007;30(9): 1213-1219.

17. Steenari MR, Vuontela V, Paavonen EJ, Carlson S, Fjallberg M, Aronen ET. Working memory and sleep in 6- to 13-year-old schoolchildren. J Am Acad Child Adolesc Psychiatry. 2003;42(1):85-92.

18. Chervin RD, Clarke DF, Huffman JL, et al. School performance, race, and other correlates of sleep-disordered breathing in children. Sleep Med. 2003;4(1):21-27.

19. Fallone G, Acebo C, Seifer R, Carskadon MA. Experimental restriction of sleep opportunity in children: effects on teacher ratings. Sleep. 2005; 28(12):1561-1567.

20. Bruni O, Verrillo E, Miano S, Ottaviano S. Clinical and historical predictors of sleep disturbances in school-age children. Sleep Hypn. 2000;2(4):147-151.

21. Kataria S, Swanson MS, Trevathan GE. Persistence of sleep disturbances in preschool children. J Pediatr. 1987;110(4):642-646.

22. Richman N, Stevenson J, Graham P. Preschool to School: A Behavioral Study. London, UK: Academic Press; 1982.

23. Smedje H, Broman JE, Hetta J. Associations between disturbed sleep and behavioral difficulties in 635 children aged six to eight years: a study based on parents' perceptions. Eur Child Adolesc Psychiatry. 2001;10(1):1-9.

24. Stein MA, Mendelsohn J, Obermeyer WH, Amromin J, Benca R. Sleep and behavior problems in school-aged children. Pediatrics. 2001; 107(4):E60.

25. Fredriksen K, Rhodes J, Reddy R, Way N. Sleepless in Chicago: tracking the effects of adolescent sleep loss during the middle school years. Child Dev. 2004;75(1):84-95.

26. Johnson EO, Chilcoat HD, Breslau N. Trouble sleeping and anxiety/ depression in childhood. Psychiatry Res. 2000;94(2):93-102.

27. Aronen ET, Paavonen EJ, Fjallberg M, Soininen M, Torronen J. Sleep and psychiatric symptoms in school-age children. $J$ Am Acad Child Adolesc Psychiatry. 2000;39(4):502-508.

28. Bates JE, Viken RJ, Alexander DB, Beyers J, Stockton L. Sleep and adjustment in preschool children: sleep diary reports by mothers relate to behavior reports by teachers. Child Dev. 2002;73(1):62-74.

29. Paavonen EJ, Almqvist F, Tamminen T, et al. Poor sleep and psychiatric symptoms at school: an epidemiological study. Eur Child Adolesc Psychiatry. 2002;11(1):10-17. 
30. Saarenpaa-Heikkila O, Laippala P, Koivikko M. Subjective daytime sleepiness in schoolchildren. Fam Pract. 2000;17(2):129-133.

31. Gregory AM, O'Connor TG. Sleep problems in childhood: a longitudinal study of developmental change and association with behavioral problems. JAm Acad Child Adolesc Psychiatry. 2002;41(8): 964-971.

32. Zuckerman B, Stevenson J, Bailey V. Sleep problems in early childhood: continuities, predictive factors, and behavioral correlates. Pediatrics. 1987;80(5):664-671.

33. Boergers J, Hart C, Owens JA, Streisand R, Spirito A. Child sleep disorders: associations with parental sleep duration and daytime sleepiness. J Fam Psychol. 2007;21(1):88-94.

34. Durand VM, Mindell JA. Behavioral treatment of multiple childhood sleep disorders. Effects on child and family. Behav Modif. 1990;14(1):37-49.

35. Richman N, Douglas J, Hunt H, Lansdown J, Levere R. Behavioral methods in the treatment of sleep disorders - a pilot study. $J$ Child Psychol Psychiatry. 1985;26(4):581-590.

36. Ramchandani P, Wiggs L, Webb V, Stores G. A systematic review of treatments for settling problems and night waking in young children. BMJ. 2000;320(7229):209-213.

37. Reid MJ, Walter AL, O'Leary SG. Treatment of young children's bedtime refusal and nighttime wakings: a comparison of "standard" and graduated ignoring procedures. J Abnorm Child Psychol. 1999; 27(1):5-16.

38. Sadeh A. Assessment and intervention for infant night waking: parental reports and activity-based home monitoring. J Consult Clin Psychol. 1994;62(1):63-68.

39. Wolfson A, Lacks P, Futterman A. Effects of parent training on infant sleeping patterns, parents' stress, and perceived parental competence. $J$ Consult Clin Psychol. 1992;60(1):41-48.

40. Wolfson AR. Working with parents on developing efficacious sleep/wake habits for infants and young children. In: Briesmeister JM, Schaefer CE, editors. Handbook of Parent Training: Parents as Co-Therapists for Children's Behavior Problems. New York, NY: John Wiley and Sons, Inc; 1998.

41. Pinilla T, Birch LL. Help me make it through the night: behavirol entrainment breastfed infants' sleep patterns. Pediatrics. 1993;91(2): 436-444.

42. Kerr SM, Jowett SA, Smith LN. Preventing sleep problems in infants: a randomized controlled trial. J Adv Nurs. 1996;24(5):938-942; Doi: 10.111 1/1365-2648.ep8550111.

43. Seymour FW, Brock P, During M, Poole G. Reducing sleep disruptions in young children: evaluation of therapist-guided and written information approaches: a brief report. J Child Psychol Psychiatry. 1989;30(6):913-918.

44. Weir IK, Dinnick S. Behaviour modification in the treatment of sleep problems occurring in young children: a controlled trial using health visitors as therapists. Child Care Health Dev. 1988;14(5):355-367.

45. Hiscock H, Wake M. Randomised controlled trial of behavioral infant sleep intervention to improve infant sleep and maternal mood. $B M J$. 2002;324(7345):1062-1065.

46. Wiggs L, Stores G. Behavioural treatment for sleep problems in children with severe intellectual disabilities and daytime challenging behaviour: effect on mothers and fathers. Br J Health Psychol. 2001; 6(Pt 3):257-269.

47. Christodulu KV, Durand VM. Reducing bedtime disturbance and night waking using positive bedtime routines and sleep restriction. Focus Autism Other Dev Disabl. 2004;19(3):130-139.

48. Graziano AM, Mooney KC. Family self-control instruction for children's nighttime fear reduction. J Consult Clin Psychol. 1980;48(2): 206-213.

49. Graziano AM, Mooney KC. Behavioral treatment of "nightfears" in children: maintenance of improvement at 2 1/2- to 3-year follow-up. J Consult Clin Psychol. 1982;50(4):598-599.

50. Giebenhain JE, O'Dell SL. Evaluation of a parent-training manual for reducing children's fear of the dark. J Appl Behav Anal. 1984;17(1): $121-125$.
51. Ollendick TH, Hagopian LP, Huntzinger RM. Cognitive-behavior therapy with nighttime fearful children. $J$ Behav Ther Exp Psychiatry. 1991;22(2):113-121.

52. Kuhn BR, Elliott AJ. Treatment efficacy in behavioral pediatric sleep medicine. J Psychosom Res. 2003;54(6):587-597.

53. Mindell JA, Kuhn B, Lewin DS, Meltzer LJ, Sadeh A. Behavioral treatment of bedtime problems and night wakings in infants and young children - an American Academy of Sleep Medicine review. Sleep. 2006;29(10):1263-1276.

54. Sadeh A. Cognitive-behavioral treatment for childhood sleep disorders. Clin Psychol Rev. 2005;25(5):612-628.

55. Morin CM. Insomnia: Psychological Assessment and Management. New York, NY: Guilford Press; 1993.

56. Manber R, Bootzin R, Acebo C, Carskadon M. The effects of regularizing sleep-wake schedules on daytime sleepiness. Sleep. 1996; 19:432-441.

57. Anbar RD, Slothower MP. Hypnosis for treatment of insomnia in school-age children: a retrospective chart review. BMC Pediatr. 2006;6:23.

58. Morin CM, Culbert JP, Schwartz SM. Nonpharmacological interventions for insomnia: a meta-analysis of treatment efficacy. Am J Psychiatry. 1994;151(8):1172-1180.

59. Murtagh DR, Greenwood KM. Identifying effective psychological treatments for insomnia: a meta-analysis. J Consult Clin Psychol. 1995; 63(1):79-89.

60. Chambers MJ, Alexander SD. Assessment and prediction of outcome for a brief behavioral insomnia treatment program. JBehav Ther Exp Psychiatry. 1992;23(4):289-297.

61. Bootzin RR, Nicassio PM. Behavioral treatments for insomnia. In: Hersen M, Eisler RM, Miller PM, editors. Progress in Behavior Modification. New York, NY: Academic Press; 1978.

62. Iglowstein I, Jenni OG, Molinari L, Largo RH. Sleep duration from infancy to adolescence: reference values and generational trends. Pediatrics. 2003;111(2):302-307.

63. Gulotta G, Ercolin D. La suggestionabilita dei bambini: Uno studio empirico. Psicologia e Giustizia. 2004;5:1-19.

64. Hart C, Hart BB. The use of hypnosis with children and adolescents. Aust J Clin Exp Hypn. 1997;25:118-126.

65. Morgan AH, Hilgard ER. Age differences in susceptibility to hypnosis. IntJ Clin Exp Hypn. 1973;21:78-85.

66. King N, Cranstoun F, Josephs A. Emotive imagery and children's night-time fears: a multiple baseline design evaluation. $J$ Behav Ther Exp Psychiatry. 1989;20(2):125-135.

67. Olness KN. Hypnotherapy: a useful tool for busy pediatricians. Contemp Pediatr. 1985;7:66-78.

68. Olness KN, Gardner GG. Hypnosis and Hypnotherapy with Children. Philadelphia, PA: Grune and Stratton; 1988.

69. Schlarb AA, Gulewitsch MD. Review: Wenn der Sandmann kommt - wirkt Hypnotherapie bei Kindern mit Schlafstorungen? Hypnose-ZHH. 2011:6(1+2).

70. Contos A. The case of how the boogie man disappeared. Aust J Clin Exp Hypn. 1999;27(2):125-135.

71. Ford R. Hypnotic treatment of a sleeping problem in an 11-year-old boy. Contemp Hypn. 1995;12:201-206.

72. Levine ES. Indirect suggestions through personalized fairy tales for treatment of childhood insomnia. Am J Clin Hypn. 1980;23(1):57-63.

73. Hammond DC. Handbook of Hypnotic Suggestions and Metaphors. New York, NY: Norton; 1990.

74. American Sleep Disorders Association, Diagnostic Classification Steering Committee. International Classification of Sleep Disorders: Diagnostic and Coding Manual, ICSD-II. Westchester, IL: American Academy of Sleep Medicine; 2005.

75. Owens JA, Dalzell V. Use of the 'BEARS' sleep screening tool in a pediatric residents' continuity clinic: a pilot study. Sleep Med. 2005;6(1): 63-69.

76. di Nardo PA, Barlow DH. Anxiety Disorders Interview Schedule-Revised (ADIS-R). New York, NY: Graywind Publications; 1988. 
77. Unnewehr S, Schneider S, Margraf J. Kinder-DIPS: Diagnostisches Interview bei Psychischen Storungen im Kindes- und Jugendalter. Berlin, Germany: Springer; 1995.

78. Minde K, Popiel K, Leos N, Falkner S, Parker K, Handley-Derry M. The evaluation and treatment of sleep disturbances in young children. J Child Psychol Psychiatry. 1993;34(4):521-533.

79. Bruni O, Ottaviano S, Guidetti V, et al. The Sleep Disturbance Scale for Children (SDSC): construction and validation of an instrument to evaluate sleep disturbances in childhood and adolescence. J Sleep Res. 1996;5(4):251-261.

80. Owens JA, Spirito A, McGuinn M. The Children's Sleep Habits Questionnaire (CSHQ): psychometric properties of a survey instrument for school-aged children. Sleep. 2000;23(8):1043-1051.
81. Sadeh A, Sharkey KM, Carskadon MA. Activity-based sleep-wake identification: an empirical test of methodological issues. Sleep. 1994; 17(3):201-207.

82. Greenberg LS, Pinsof WM. The Psychotherapeutic Process: A Research Handbook. New York, NY: Wilkins; 1986.

83. Wirth D. The significance of belief and expectancy within the spiritual healing encounter. Soc Sci Med. 1995;41(2):249-260.

84. Morgenthaler TI, Owens J, Alessi C, et al; American Academy of Sleep Medicine. Practice parameters for behavioral treatment of bedtime problems and night wakings in infants and young children. Sleep. 2006; 29(10):1277-1281.

\section{Publish your work in this journal}

Nature and Science of Sleep is an international, peer-reviewed, open access journal covering all aspects of sleep science and sleep medicine, including the neurophysiology and functions of sleep, the genetics of sleep, sleep and society, biological rhythms, dreaming, sleep disorders and therapy, and strategies to optimize healthy sleep. The journal welcomes

\section{Dovepress}

original research, clinical \& epidemiological studies, reviews \& evaluations, case reports and extended reports. The manuscript management system is completely online and includes a very quick and fair peerreview system, which is all easy to use. Visit http://www.dovepress.com/ testimonials.php to read real quotes from published authors. 